\title{
CACTACEAE NO PARQUE ESTADUAL DO IBITIPOCA, MINAS GERAIS, BRASIL ${ }^{1}$
}

\author{
DIEGO RAFAEL GONZAGA*,DANIELA C. ZAPPI**, SAMYRA GOMES FURTADO*** \& \\ LUIZ MENINI NETO*
}

\begin{abstract}
* Centro de Ensino Superior de Juiz de Fora, Campus Arnaldo Janssen, Luz Interior 345, Santa Luzia, 36030 -
776, Juiz de Fora, MG, Brasil. Autor para correspondência: e-mail: diego.gonzaga@gmail.com

${ }_{* *}$ Gardens by the Bay, Singapore/Royal Botanic Gardens, Kew, UK

*** Universidade Federal de Juiz de Fora, Instituto de Ciências Biológicas, Martelos, 36036-330 - Juiz de Fora,
\end{abstract} MG, Brasil.

\begin{abstract}
Cactaceae in the Parque Estadual do Ibitipoca, Minas Gerais, Brazil). The Parque Estadual do Ibitipoca (PEIB) is located in southeastern Minas Gerais, between the municipalites of Lima Duarte, Santa Rita de Ibitipoca and Bias Fortes $\left(21^{\circ} 40^{\prime}-21^{\circ} 44^{\prime} S\right.$ and $\left.43^{\circ} 52^{\prime}-43^{\circ} 55^{\prime} \mathrm{W}\right)$. The park has an area of 1.488 ha, with altitudes between 1.100 to 1.784 m.s.m., and the predominant vegetation is the campo rupestre. The aim of the present study was to conduct a survey of Cactaceae in PEIB. The family comprises four genera and seven species, as follows: Arthrocereus melanurus subsp. magnus, Hatiora salicornioides, Rhipsalis elliptica, Rhipsalis floccosa subsp. pulvinigera, R. juengeri, R. pulchra and Schlumbergera opuntioides. Identification keys, descriptions, illustrations, taxonomic and ecologic comments are provided for the species treated.
\end{abstract}

Key words: Atlantic Forest, floristics, Mantiqueira Range, taxonomy.

Resumo - (Cactaceae no Parque Estadual do Ibitipoca, Minas Gerais, Brasil). O Parque Estadual do Ibitipoca está localizado no sudeste de Minas Gerais, entre os municípios de Lima Duarte, Santa Rita de Ibitipoca e Bias

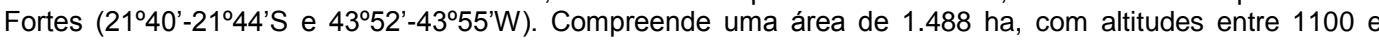
1748 m.s.m., e vegetação com predominância de campos rupestres. O objetivo do presente estudo foi realizar um levantamento de Cactaceae no PEIB. A família está representada na área por quatro gêneros e sete espécies, listados a seguir: Arthrocereus melanurus subsp. magnus, Hatiora salicornioides, Rhipsalis elliptica, Rhipsalis floccosa subsp. pulvinigera, R. juengeri, R. pulchra e Schlumbergera opuntioides. São apresentadas chave de identificação, descrições, ilustrações, comentários taxonômicos e ecológicos para as espécies.

Palavras-chave: Floresta Atlântica, florística, Serra da Mantiqueira, taxonomia.

\section{Introdução}

Cactaceae compreende 124 gêneros e 1438 espécies distribuídas quase que exclusivamente na América tropical e subtropical, desde o Canadá até a Patagônia. Apenas Rhipsalis baccifera (J.M. Muell.) Stearn ocorre na África e Ásia (Hunt et al. 2006). Os principais centros de diversidade e endemismo da família estão localizados no México e sudoeste dos Estados Unidos, na região central da cordilheira dos Andes, especialmente no Peru e na Bolívia e a região leste do Brasil, compreendendo diversos tipos de habitats (Taylor \& Zappi 2004).

No Brasil ocorrem cerca de 330 espécies distribuídas em todos os domínios fitogeográficos. Destas, 182 são endêmicas do país, estando o maior nível de endemismo concentrado na Região Sudeste (com cerca de 100 espécies) (Silva et al. 2011). Em relação ao número de gêneros, 17 são endêmicos (Zappi et al. 2014), destacando-se o leste do país, com aproximadamente $74 \%$ das espécies endêmicas (Taylor \& Zappi 2004).
O Parque Estadual do Ibitipoca (PEIB) é uma Unidade de Conservação (UC) situada no sudeste do estado de Minas Gerais, entre os municípios de Lima Duarte, Santa Rita de Ibitipoca e Bias Fortes. Está inserida no Complexo da Mantiqueira, fazendo parte do Domínio Atlântico (CETEC 1983) e considerada como área prioritária para a conservação da flora de Minas Gerais, na categoria de "Importância Biológica Especial" (Drummond et al. 2005). Vários estudos realizados reforçam a importância florística dessa UC (e.g., Menini Neto et al. 2007; Monteiro \& Forzza 2008; Menini Neto et al. 2009; Barberena et al. 2010; Blaser et al. 2011; Ferreira et al. 2011; Ferrero \& Mello-Silva 2011; Andrade \& Forzza 2012; Lopes \& Mello-Silva 2012).

O objetivo deste estudo é apresentar o tratamento taxonômico de Cactaceae para o Parque Estadual do Ibitipoca, contribuindo com o conhecimento florístico da UC, bem como do estado de Minas Gerais. São apresentadas chaves de identificação, descrições, ilustrações, comentários taxonômicos e ecológicos para as espécies.

\footnotetext{
${ }^{1}$ Parte do trabalho de conclusão de curso do primeiro autor no Curso de Ciências Biológicas do Centro de Ensino Superior de Juiz de Fora.
}

DOI: 10.11606/issn.2316-9052.v32i1p1-8

Bol. Bot. Univ. São Paulo, São Paulo, v. 32, n. 1, p. 1-8, 2014 


\section{Material e métodos}

O Parque Estadual do Ibitipoca (PEIB) foi criado em 4 de julho de 1973, pela Lei $\mathrm{n}^{\circ} 6.126$ (Forzza et al. 2013). Esta UC está situada no sudeste

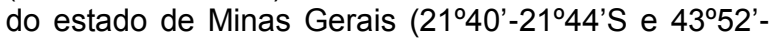
$\left.43^{\circ} 55^{\prime} \mathrm{W}\right)$, apresentando área de $1.488 \mathrm{ha}$, em uma região com relevo bastante acidentado, com paredões rochosos e grutas por toda sua extensão, sendo o Pico da Lombada o ponto mais alto, a 1.784 m.s.m. (Menini Neto et al. 2007). O clima da região é classificado como Cwb de Köppen, mesotérmico úmido, com verões amenos e invernos secos. A precipitação anual média é de $1.532 \mathrm{~mm}$ e a temperatura média de $18,9{ }^{\circ} \mathrm{C}$ (CETEC 1983).

O PEIB apresenta um mosaico de formações vegetacionais, das quais o campo rupestre ocupa a maior extensão, sendo também encontradas diversas formações florestais (Menini Neto et al. 2007). Esta UC destaca-se por ser a menor unidade de conservação do estado que abriga áreas de campo rupestre, sendo também uma das unidades de conservação mais visitadas no Brasil (Salimena-Pires 1997, Vitta 2002).

Foram examinados para este estudo materiais provenientes do PEIB de coletas específicas (realizadas entre setembro de 2012 e agosto de 2013) e de coleções depositadas nos herbários CESJ e RB (acrônimos segundo Thiers 2013). Os exemplares foram fotografados em campo e as fotos publicadas no formato "Rapid Color Guide do Field Museum of Chicago", (disponível em: http://fm2.fieldmuseum.org/ plantguides/iter_guide.asp?type $=$ full\&id=622\&link=499 \%20Cactaceae\%20de\%20lbitipoca.pdf). Dados referentes a estrutura floral de Schlumbergera opuntioides, foram obtidos em Zappi et al. (2007).

\section{Resultados e Discussão}

As Cactaceae do PEIB estão representadas por sete espécies, distribuídas em quatro gêneros: Arthrocereus melanurus subsp. magnus N.P. Taylor \& Zappi, Hatiora salicornioides (Haw.) Britton \& Rose, Rhipsalis elliptica G. Lindb. ex K. Schum., Rhipsalis floccosa subsp. Pulvinigera (G. Lindb.) Barthlott \& N.P. Taylor, R. juengeri Barthlott \& N.P. Taylor, R. pulchra Loefgr. e Schlumbergera opuntioides (Loefgr. \& Dusén) D.R. Hunt. Todas as espécies de Rhipsalis registradas no PEIB apresentam forma de vida epifítica, enquanto duas espécies possuem hábito arenícola ou rupícola ( $A$. melanurus subsp. Magnus e $S$. opuntioides) e uma espécie ocorre tanto como epífita quanto rupícola (H. salicornioides).

A representatividade do gênero Rhipsalis no PEIB reflete o fato de este ser o gênero mais rico em número de espécies dentre as Cactaceae no Brasil e da Floresta Atlântica na região Sudeste do país ser o centro de diversidade do gênero (Zappi et al. 2014), no qual a maioria das espécies é epífita, forma de vida que se destaca devido à presença de florestas nebulares nas cotas altimétricas mais elevadas (Menini Neto et al. 2009).

Em Minas Gerais, a maior concentração de tratamentos para as Cactaceae está localizada na Cadeia do Espinhaço (Zappi 1990; Taylor \& Zappi 1991; Zappi \& Taylor 2003; Taylor \& Zappi 2004; Zappi \& Taylor 2008). Em contrapartida, apenas um estudo específico foi realizado na região da Zona da Mata, na Serra Negra, município de Rio Preto (Gonzaga et al. 2014).

Dentre as Cactaceae registradas no PEIB, merece destaque Arthrocereus melanurus subsp. magnus, subespécie anteriormente considerada endêmica do Parque (Taylor \& Zappi 1997), associada aos afloramentos quartzíticos e solos arenosos do campo rupestre, a qual foi registrada recentemente na Serra Negra (Gonzaga et al. 2014), região que dista ca. $25 \mathrm{~km}$ do PEIB.

Dentre as espécies registradas neste estudo, são citadas como ameaçadas de extinção no Brasil, Arthrocereus melanurus subsp. magnus e Schlumbergera opuntioides, com o status "Quase Ameaçada" (NT) (Silva et al. 2011). Schlumbergera opuntioides é considerada no status "Vulnerável" (VU) pela IUCN (2013). Para Minas Gerais são listados Arthrocereus melanurus subsp. magnus no status "Criticamente em Perigo" (CR), Schlumbergera opuntioides no status "Vulnerável" (VU) (Fundação Biodiversitas 2007).

\section{Tratamento taxonômico}

\section{Cactaceae Juss.}

Plantas arborescentes, arbustivas, subarbustivas a herbáceas, rupícolas, terrícolas ou epífitas, geralmente suculentas e com caule fotossintetizante, às vezes segmentado, ramos frequentemente achatados ou colunares e costelados, ou globosos. Ramos curtos do tipo braquiblasto transformados em aréolas, originando folhas (em Pereskia Mill.), folhas escamiformes, espinhos de morfologia variada, e também outros ramos tanto vegetativos como reprodutivos. Folhas, quando presentes (como em Pereskia) alternas, simples, sem estípulas, geralmente carnosas. Inflorescência cimosa, frequentemente reduzida a uma única flor; flores geralmente vistosas, bissexuadas, actinomorfas ou ligeiramente zigomorfas; segmentos do perianto numerosos e espiralados; estames numerosos, anteras rimosas, disco nectarífero presente; ovário geralmente ínfero (raramente súpero em Pereskia), e então envolvido por um hipanto receptacular imerso no ramo vegetativo, 3-pluricarpelar, unilocular; placentação parietal, pluriovulado, estilete geralmente alongado, com estigma ramificado indicando o número de carpelos que formam o ovário. Fruto baga ou cápsula carnosa, sementes cocleariformes, envolvidas em polpa funicular transparente ou colorida, geralmente adocicada (Souza \& Lorenzi 2012). 
1. Aréolas espinescentes, espinhos pungentes; plantas rupícolas ou arenícolas

1'. Aréolas inermes ou aréolas com cerdas finas; plantas epífitas e/ou rupícolas.

2. Ramos clavados; flores amarelas a alaranjadas

2'. Ramos aplanados ou cilíndricos; flores alvas, creme-brilhante ou magenta.

3. Ramos aplanados.

4. Ramos verde-brilhantes, aréolas espinescentes, margem lisa, verde; flores zigomorfas, magenta; frutos terminais, 1 por aréola

4'. Ramos verde-escuros, aréolas glabras, margem crenada, avermelhada ou acinzentada; flores rotáceas, creme-brilhante, com ápice avermelhado; frutos laterais, $1-5$ por aréola

1. Arthrocereus melanurus subsp. magnus Ramos cilíndricos.

5. Aréolas cerdosas

5'. Aréolas glabras.

6. Ramos com crescimento acrotônico; flores alvas; frutos vermelhos; ambos terminais a subterminais.

6'.Ramos com crescimento mesotônico; flores alvas, matizadas de róseo; frutos róseos, translúcidos; ambos laterais e terminais

1. Arthrocereus melanurus subsp. magnus N.P. Taylor \& Zappi, Cact. Consensus Initiat. 3: 7. 1997.

Fig. 1.A

Arbusto ramificado, arenícola ou rupícola em campo rupestre, até 1,5-2 $\mathrm{m}$ alt., ramos costelados, verde-claros, 3-4,2 cm diâm., ramificados apenas na base (acima da base somente quando cortados), 1621 costelas, ca. $3 \times 2 \mathrm{~mm}$, aréolas $2-4 \mathrm{~mm}$ larg., distanciadas 5-8 mm entre si, espinhos pungentes 6070 por aréola, centrais $1,5-3 \mathrm{~cm}$ compr., radiais $2-5$ $\mathrm{mm}$ compr.; botão floral verde hirsuto; flores alvas, ca. $4 \times 5 \mathrm{~cm}$, de antese noturna, ca. 62 segmentos do perianto, segmentos externos do perianto lanceolados, ca. $1,8 \times 0,5 \mathrm{~cm}$, esverdeados, segmentos internos do perianto lanceolados, ca. $4 \times 1 \mathrm{~cm}$; tubo floral ca. $7 \mathrm{~cm}$ compr., dotado de tricomas castanhos; ca. 230 estames, estames do raio ca. $2,5 \mathrm{~cm}$ compr., estames centrais ca. 4,5 cm compr., estilete ca. $9,5 \mathrm{~cm}$ compr., estigma 16-lobado, lobos ca. $5 \mathrm{~mm}$ compr.; frutos globosos, verde passando a verde-acastanhado, indeiscentes, ca. $3 \mathrm{~cm}$ diâm., dotados de tricomas, sementes negras, cocleariformes, ca. $1 \mathrm{~mm}$ compr.; testa verrucosa.

Material examinado: III.1999, fl., R.G. Rodela s.n. (CESJ 36537); 16.XII.2001, fl., A. Valente 87 (BHCB, CESJ, CTES, MBM); 25.XI. 2005, fl., L.Y.S. Aona et al. 915 (RB); 20.IV.2013, fr., D.R. Gonzaga et al. 231 (CESJ).

Material adicional: MINAS GERAIS: Lima Duarte, Serra Negra, Trilha da cachoeira do Arco-Íris, 8.XII.2012, fl., D.R. Gonzaga et al. 117 (CESJ).

Arthrocereus melanurus subsp. magnus é endêmica de Minas Gerais, ocorrendo apenas no Parque Estadual do Ibitipoca (Taylor \& Zappi 1997) e Serra Negra (Gonzaga et al. 2014), apresentando hábito arenícola e/ou rupícola em campo rupestre. Foram observadas populações em diferentes pontos da unidade, como próximo do alojamento de pesquisadores, trilha para o Cruzeiro e Lombada,
Gruta dos Três Arcos, entre 1200 e 1700 m.s.m. É considerada uma espécie Quase Ameaçada (Silva et al. 2011) de acordo com os critérios da IUCN e Criticamente em Perigo segundo a Lista de Espécies Ameaçadas da Flora de Minas Gerais (Fundação Biodiversitas 2007). Diferencia-se das demais subespécies de $A$. melanurus pelo maior porte $\mathrm{e}$ diâmetro dos cladódios.

2. Hatiora salicornioides (Haw.) Britton \& Rose, Stand. Cycl. Hort. 3: 1433. 1915.

Fig. 1.B-C

Epífita ou rupícola, ramos basais lenhosos, 4-5 $\mathrm{mm}$ larg., ramos terminais herbáceos, verde-claros ou verde-escuros a avermelhados, 1,3-1,7 x 0,4-0,6 cm., fortemente clavados a cilíndricos ca. $2 \mathrm{~mm}$ larg., 2-5 ramificados, artículos 1,5-2,7 cm compr., aréolas terminais, tricomas alvos; botão floral cremeesverdeado; flores amarelo a alaranjadas, semitubulares, ca. $11 \times 5 \mathrm{~mm}$, ca. 20 segmentos do perianto, segmentos externos ovados, $2-4 \times 2 \mathrm{~mm}$, segmentos internos lanceolados, $6-9 \times 2 \mathrm{~mm}$; ca. 63 estames, filete ca. $4 \mathrm{~mm}$ compr., estilete ca. $6 \mathrm{~mm}$ compr., estigma 3-lobado, lobo ca. $1 \mathrm{~mm}$ compr.; frutos obovoides a turbinados, 5-6 x 5-7 mm, alvos, sementes castanhas ca. $1 \mathrm{~mm}$ compr., reniformes, testa levemente sulcada.

Material examinado: 19.X.2003, fl., R.C. Forzza et al. 2451 (RB); 10.III.2004, fr., R.C. Forzza et al. 3159 (MBM, RB, SPF); 21.I.2005, fr., L.C.S. Assis et al. 1093 (CESJ, MBM, RB, SPF); 6.III.2006. fr., F.R.G.Salimena et al. 1305 (CESJ); 27.X.2012, fl., fr., D.R.Gonzaga et al. 42 (CESJ).

Hatiora salicornioides é endêmica do Brasil, ocorrendo como epífita ou rupícola nos estados da Região Sudeste, além de Bahia e Paraná (Zappi et al. 2013). No Parque Estadual do Ibitipoca foi encontrada como epifítica no interior de fragmento de floresta ao 

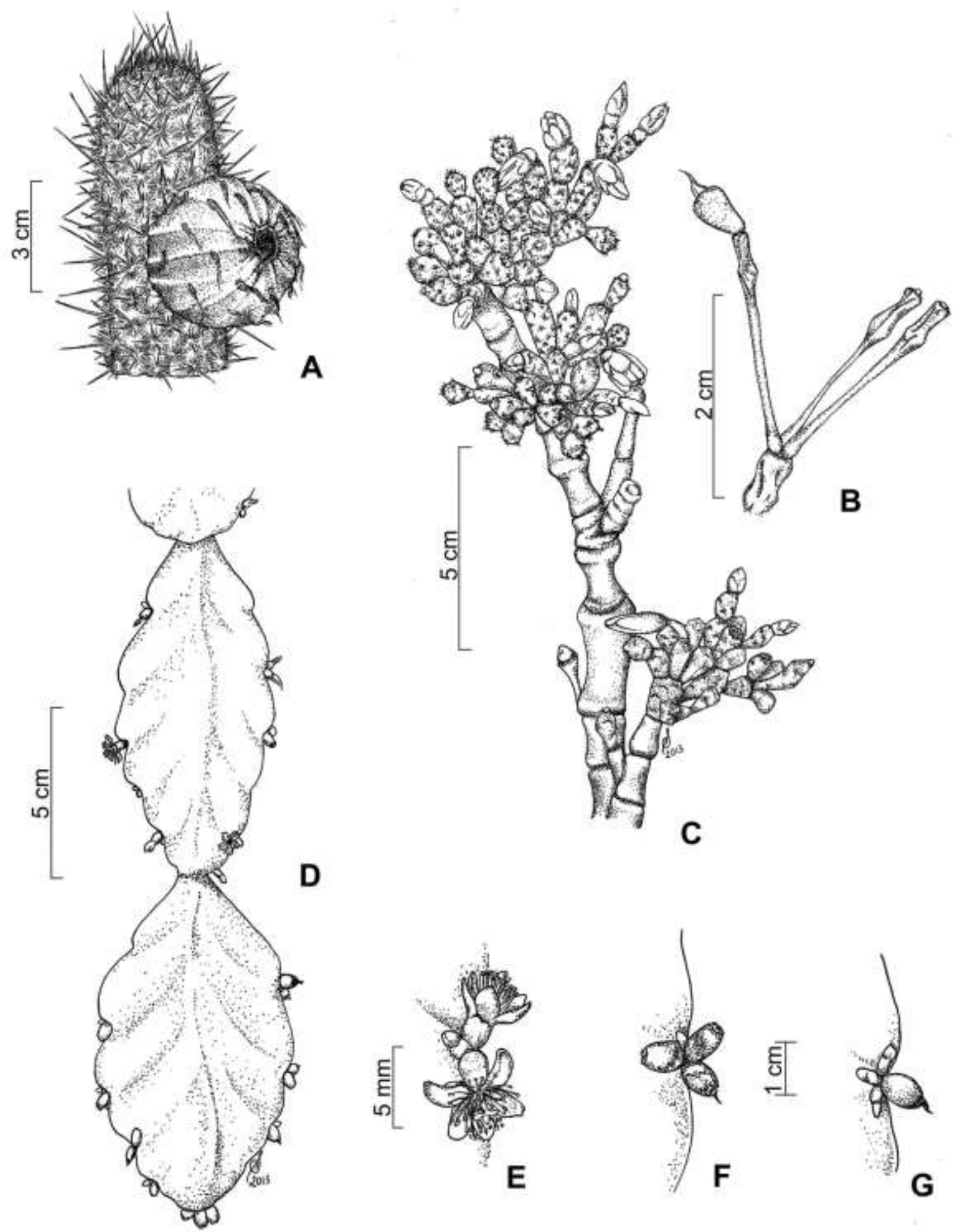

Fig. 1 - A. Arthrocereus melanurus subsp. magnus, detalhe do caule com fruto; B-C. Hatiora salicornioides, B. detalhe do ramo da forma epifítica, C. hábito da forma rupícola; D-G. Rhipsalis elliptica, D. ramo, E. detalhe de botão e flores; F-G. detalhes de botões e frutos. (A - Gonzaga 231; B - Gonzaga 42; C - Forzza 2451; D-G - Gonzaga 230). 
lado da entrada do parque e em proximidades da Gruta dos Três Arcos e como rupícola em paredões da Gruta do Cruzeiro, Prainha das Elfas e Ponte de Pedra, e como arenícola e/ou terrícola em áreas próximas à Janela do Céu, em altitudes entre 1200 e 1600 m.s.m. Os espécimes rupícolas apresentam engrossamento na base e artículos ca. 1,7 cm compr., e ramos terminais $1,3 \times 0,4-0,6 \mathrm{~cm}$ e os espécimes epífitas artículos 2,5-2,7 cm compr., e ramos terminais $1,8 \times 0,2 \mathrm{~cm}$. Apresenta ramos terminais clavados que a diferencia das demais espécies do gênero.

\section{Rhipsalis Gaertn.}

Plantas pendentes quando epífitas, ou eretas a decumbentes quando rupícolas; ramos segmentados, ramos apicais geralmente com ramificação acrotônica (partindo da ponta do ramo) ou às vezes mesotônica (partindo do meio do ramo), sem espinhos pungentes, apesar de apresentar cerdas; segmentos cilíndricos, angulosos, alados ou aplanados, às vezes com costelas; aréolas inconspícuas ( $R$. pulchra) até conspícuas, cerdosas quando jovens e/ou lanosas apenas após florescer, subtendidas por pequenas escamas; aréolas compostas terminais muitas vezes presentes. Botões florais erumpentes a partir de aréolas imersas ou desenvolvendo-se na superfície dos ramos. Flores de antese diurna, rotáceas ou campanuladas, laterais ou pêndulas, 1-13 por aréola, alvas, amarelas ou rosadas, raramente avermelhadas; pericarpelo mais ou menos liso, desprovido de aréolas cerdosas ou espinescentes (exceto $R$. pilocarpa); tubo floral ausente ou inconspícuo; segmentos do perianto 5-18, reflexos a campanulados, delgados, translúcidos; estames exsertos ou inclusos com relação ao perianto. Fruto subgloboso a elipsoide, nunca anguloso, liso (exceto $R$. pilocarpa), alvo, alaranjado, rosa ou violáceo, polpa mucilaginosa; sementes 1-1,7 mm, espessas, castanhos-escuras a negras, paredes periclinais das células da testa convexas ou planas (Zappi et al. 2007).

Rhipsalis apresenta 32 espécies, das quais 29 são endêmicas do Brasil. Está distribuído nas regiões Norte (Amapá, Pará, Amazonas), Nordeste (Maranhão, Ceará, Paraíba, Pernambuco, Bahia, Sergipe), Centro-Oeste (Mato Grosso, Goiás), Sudeste (Minas Gerais, Espírito Santo, São Paulo, Rio de Janeiro) e Sul (Paraná, Santa Catarina, Rio Grande do Sul) (Zappi et al. 2013).

3.1 Rhipsalis elliptica G. Lindb. ex K. Schum., FI. bras. 4(2): 293. 1890.

Fig. 1.D-G

Epífita, ramos aplanados, verde-escuros, ramos aplanados alongados 8-13,5 x 1,5-3,5 cm, margem crenada, avermelhada ou acinzentada, crescimento acrotônico, aréolas glabras, distanciadas $1,4-2,1 \mathrm{~cm}$ umas das outras, ramos terminais ovados
9,5-13 x 6,4-7,5 cm; botões florais rosa-forte; flores creme-brilhantes com ápice avermelhado, 1-5 por aréola, rotáceas, ca. $5 \times 7 \mathrm{~mm}, 8$ segmentos do perianto, patente-reflexos, segmentos externos ovados, ca. $3,2 \times 4 \mathrm{~mm}$, segmentos internos largamente elípticos, ca. $5 \times 4 \mathrm{~mm}$, pericarpelo ca. $4 \times$ $3 \mathrm{~mm}$, estames ca. 54, filetes ca. $5 \mathrm{~mm}$ compr., estilete ca. $4 \times 1 \mathrm{~mm}$, estigma ca. $2 \times 4 \mathrm{~mm}$ diam., estigma 4-lobado, lobos ca. $1,5 \mathrm{~mm}$; frutos magenta a vináceos, laterais, 1-5 por aréola, globoso-truncados no ápice, $8-10 \times 7-8 \mathrm{~mm}$, sementes negras de testa rugosa ca. $1 \mathrm{~mm}$ compr., formato sub-piriforme a piriforme.

Material examinado:11.III.2004, fr., R.C. Forzza. et al. 3226 (MBM, RB); 20.IX.2006, fr., R.C. Forzza et al. 4256 (RB); 20.IV.2013, bot., fl., fr., D.R. Gonzaga et al. 230 (CESJ).

Rhipsalis elliptica é endêmica do Brasil, ocorrendo na Bahia, Mato Grosso, Goiás, Minas Gerais, Rio de Janeiro e Paraná, nos domínios da Caatinga, Cerrado e Floresta Atlântica (Zappi et al. 2013). No PEIB é encontrada apenas nas florestas nebulares da Janela do Céu e Gruta do Cruzeiro em altitude em torno de 1600 m.s.m. Se diferencia das demais espécies de Rhipsalis que ocorrem no Parque, devido aos ramos aplanados. Forzza et al. (2013) trataram esta espécie como R. russellii Britton \& Rose, erro que se deu em virtude da ausência de flores no material examinado. Deste modo, no presente estudo a correta identidade da espécie pôde ser obtida, após a análise de exemplar florido, sendo R. elliptica reconhecida pela presença de 1-5 flores ou frutos por aréola (vs. 5-10 flores em R. russellii), e flores maiores com 40-56 estames (vs. flores menores com 12-14 estames).

3.2 Rhipsalis floccosa subsp. pulvinigera (G. A. Lindb.) Barthlott \& N.P. Taylor, Bradleya 13: 55. 1995.

Fig. 2.A

Epífita, ramos cilíndricos, verde-escuros a verdeacinzentados, 3-5 mm diâm., ramos terminais 6-21 x 0,3-0,5 cm, crescimento acrotônico, aréolas cerdosas ao longo dos ramos, cerdas alvas e numerosas; botões florais creme, eruptentes; flores terminais a subterminais, alvas, 1 por aréola, rotáceas, 7-9 x 10-12 $\mathrm{mm}$, ca. 16 segmentos do perianto, segmentos externos triangulares a ovados $5-6 \times 3-4 \mathrm{~mm}$, segmentos internos lanceolados, 7-10 x 3-4 mm, estames 93-140, filetes 3-6 mm compr., estilete 4-6 mm compr., estigma 4-5 lobado, lobos 1,5-2 mm compr.; frutos alvos, 5-8 $x$ 7-8 mm, globosos, levemente truncados no ápice, segmentos do perianto persistentes; sementes castanho-escuras a avermelhadas, ca. $2 \times 1 \mathrm{~mm}$, reniformes, testa lisa, nítida.

Material examinado: 25.IX.2001, fl., L.C. Giordano et al. 2424 (RB); 25.IX.2001, fl., R. Marquete et al. 3069 (RB); 9.III.2004, fr., R.C. Forzza et al. 3062 (CEPEC, MBM, RB, SP, SPF); 28.X.2012, fr., D.R. Gonzaga et al. 49 (CESJ); 10.VIII.2013, fl., D.R.Gonzaga 265 (CESJ). 


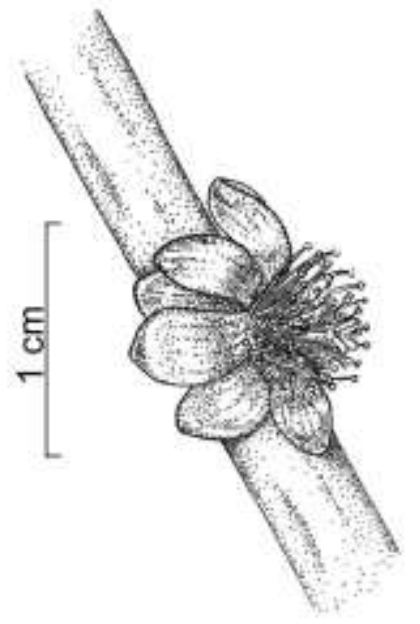

A
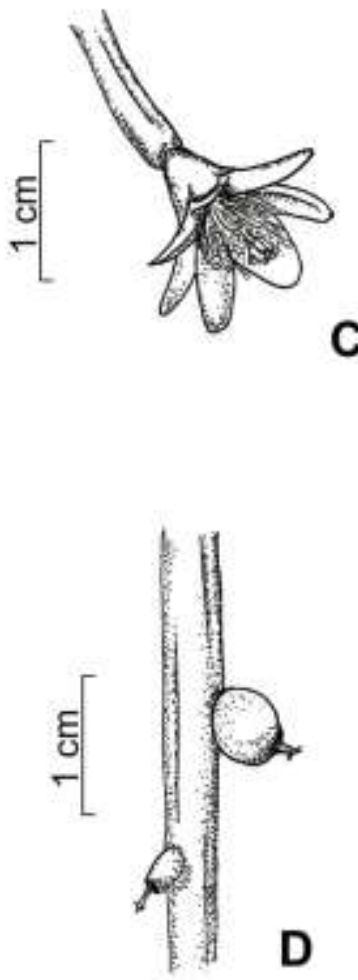
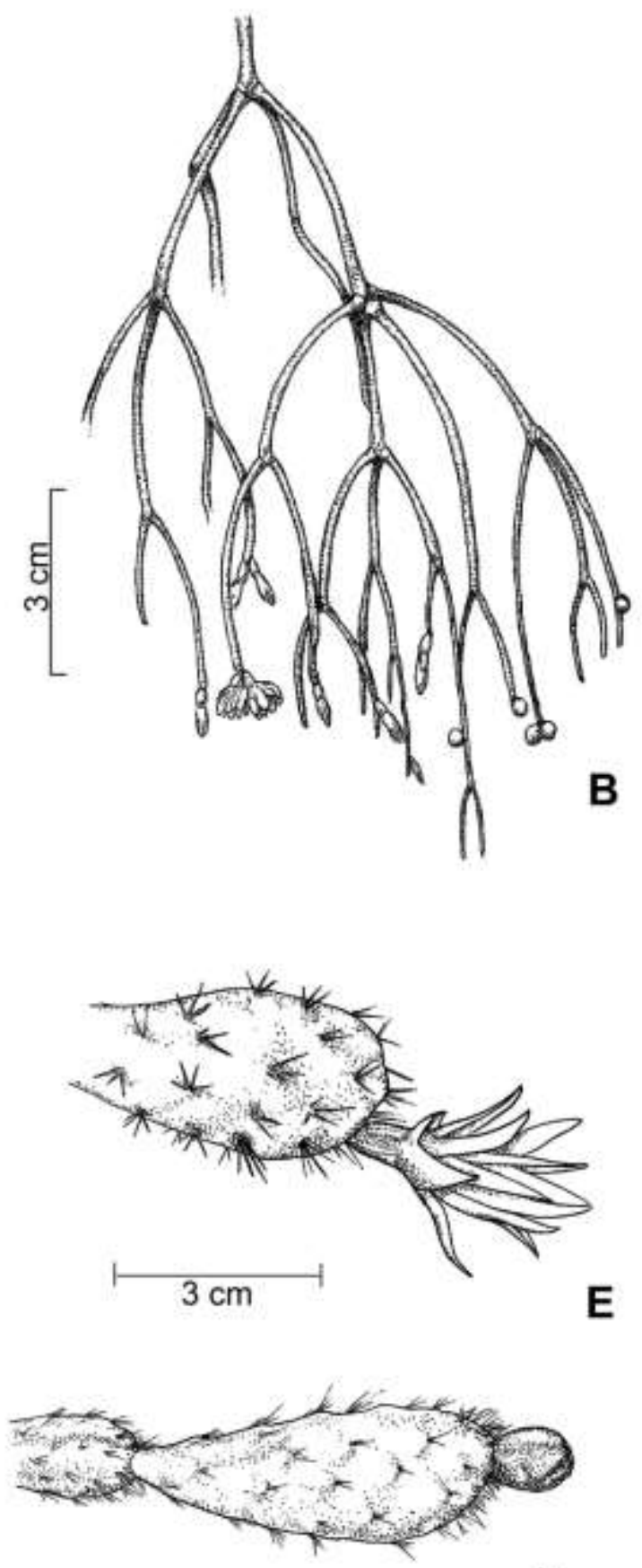

$\mathbf{F}$

Fig. 2 - A. Rhipsalis floccosa subsp. pulvinigera, detalhe da flor; B. Rhipsalis juengeri, hábito; C-D. Rhipsalis pulchra, C. detalhe da flor; D. detalhe dos frutos; E-F. Schlumbergera opuntioides, E. detalhe da flor, F. detalhe do fruto. (A - Gonzaga 265; B Gonzaga 50; C - Gonzaga 264; D - Gonzaga 48; E - Zappi 258; F - Gonzaga 46). 
Rhipsalis floccosa subsp. pulvinigera ocorre em Pernambuco, Bahia, Sergipe e nos estados das regiões Sudeste e Sul, sendo endêmica do Brasil (Zappi et al. 2013). No Parque Estadual do Ibitipoca é encontrada como epífita nas florestas nebulares do Lago Negro, Gruta do Cruzeiro e na Mata Grande, em altitudes entre 1400 e 1650 m.s.m., as flores possuem antese diurna, e se fecham no período noturno, tendo duração de dois ou três dias. É uma espécie bem caracterizada pela presença de aréolas cerdosas, nas quais se inserem botões, flores e frutos, podendo ser diferenciada das demais subespécies de $R$. floccosa devido às flores serem eruptentes e esparsamente dispostas sobre os ramos.

3.3 Rhipsalis juengeri Barthlott \& N.P.Taylor, Bradleya 13: 69. 1995.

Fig. 2.B

Epífita, muito ramificada, ramos cilíndricos, delicados, pendentes, verde-escuros, ramos basais 2$3 \mathrm{~mm}$ diam.,ramos terminais $2-3$ ramificados, 1,8-5,2 $\mathrm{x}$ $0,1 \mathrm{~cm}$, crescimento acrotônico, aréolas glabras no ápice dos ramos, glabras; botões florais alvos; flores terminais a sub-terminais, alvas, 1-4 por aréola, campanuladas, pêndulas, ca. 8-10 x 3-4 mm, pericarpelo ca. $2 \mathrm{~mm}$ compr., segmentos do perianto 10-14, segmentos externos ovados, $3-4 \times 3 \mathrm{~mm}$, segmentos internos lanceolados, 6-10 x 2-3 mm estames 35-43, filetes 4-5 mm compr., estilete 6-7 x 1 $\mathrm{mm}$, estigma 3-5 lobado, lobos ca. $2 \mathrm{~mm}$ compr.; frutos globoso-truncados, 5-6 x 5-6 mm, vermelhos, segmentos do perianto persistentes, 1-2 frutos por aréola, sementes reniformes a sub-reniformes, castanho-avermelhadas a negras, testa levemente rugosa a lisa, nítida, ca. $2 \times 1 \mathrm{~mm}$.

Material examinado: 2.XII.2003, fr., L. Menini Neto \& R.J.V. Alves 63 (CESJ); 11.III.2004, fr., R.C.Forzza et al. 3204 (RB); 22.XI.2004, fl., R.C. Forzza et al. 3611 (RB); 28.X.2012, fl., fr., D.R.Gonzaga et al. 50 (CESJ).

Rhipsalis juengeri é endêmica do Brasil, ocorrendo em Minas Gerais, Espírito Santo e São Paulo (Zappi et al. 2013). No PEIB ocorre nas florestas de grota, próximo às Grutas do Cruzeiro e Três Arcos, em altitudes entre 1500 e 1650 m.s.m. Pode ser diferenciada das demais espécies de Rhipsalis do PEIB por apresentar flores alvas, pendentes, terminais e frutos vermelhos truncados. É muito confundida, em materiais herborizados, com Rhipsalis camposportoana Loefgr. (a qual não tem ocorrência registrada para Minas Gerais), devido aos frutos truncados e de maior dimensão.

3.4 Rhipsalis pulchra Löefgr., Arch. Jard. Bot. Rio de Janeiro 1: 75. 1915.

Fig. 2.C-D

Epífita, ramos cilíndricos desiguais, ramos basais 2-3 $\mathrm{mm}$ diam., nós engrossados nas ramificações, ramos apicais ca. $2 \mathrm{~mm}$ diam., crescimento mesotônico, aréolas glabras ao longo dos ramos; botões florais creme a róseos ao longo dos ramos; flores laterais, alvas, matizadas de róseo, 1-2 por aréola, campanuladas, ca. $9 \times 8 \mathrm{~mm}$ compr., ca. 12 segmentos do perianto, segmentos externos ovados a triangulares ca. $2,5 \times 3 \mathrm{~mm}$, segmentos internos lanceolados $6-7 \times 3 \mathrm{~mm}$, pericarpelo ca. $5 \times 4$ $\mathrm{mm}$, estames ca. 70 , filetes $4-5 \mathrm{~mm}$ compr., estilete ca. $6 \mathrm{~mm}$ compr., estigma 2-4 lobado, lobos ca. $2 \mathrm{~mm}$ compr.; frutos globosos truncados, ca. $6 \times 4 \mathrm{~mm}$, róseos translúcidos, 1 por aréola, sementes de testa rugosa ca. 1,5 mm compr., sub-reniformes, negras.

Material examinado: 11.III.2004, fr., R.C. Forzza et al. 3227 (RB, SP); 11.VIII.2005, fl., R.C. Forzza et al. 4147 (MBM, RB, SPF); 27.VIII.1991, bot., D.C. Zappi 260 (CESJ, SPF); 28.X.2013, fr., D.R.Gonzaga et al. 48 (CESJ); 10.VIII.2013, fl., D.R.Gonzaga 264 (CESJ).

Rhipsalis pulchra é endêmica do Brasil, ocorrendo em Minas Gerais, São Paulo e Rio de Janeiro (Zappi et al. 2013). No PEIB há registros de ocorrência em floresta de grota próximo à entrada do Parque, em altitude de 1200 m.s.m., e Gruta do Cruz, em altitude de 1650 m.s.m., visitada por abelhas. Diferencia-se das demais espécies do gênero ocorrentes no PEIB pelos ramos grossos com aréolas glabras e segmentos do perianto persistentes nos frutos.

4. Schlumbergera opuntioides (Loefgr. \& Dusén) D.R.Hunt, Kew Bull. 23(2): 2601969.

Fig. 2.E-F

Epífita ou rupícola, ramos aplanados, verdebrilhantes, basal ca. $0,7 \mathrm{~mm}$ larg., cilíndrico com aréolas cerdosas laterais, terminais 0,6-0,8 x 1,7-3,2 $\mathrm{cm}$, margem lisa, verdes, tricomas dourados; botões florais magenta, terminais; flores magenta, terminais, 1-2 por ramo, zigomorfas, ca. $3,7 \mathrm{~cm}$ compr., segmentos externos do perianto lanceolados, reflexos, segmentos internos lanceolados, eretos, pericarpelo ca. $6 \mathrm{~mm}$, estames 80-85, filetes 1-1,5 mm, estilete ca. $3,5 \mathrm{~cm}$ compr., estigma 2-lobado, lobos ca. $2 \mathrm{~mm}$ compr.; fruto globoso, terminal, imaturo verde, sementes piriformes, lisas, brilhantes.

Material examinado: 27.VIII.1991, fl., D.C. Zappi 258 (CESJ, SPF); 11.III.2004, fr., R.C. Forzza et al. 3180 (RB); 11.VIII.2005, fl., R.C. Forzza et al. 4151 (RB); 28.X.2012, fr., D.R. Gonzaga et al. 46 (CESJ).

Schlumbergera opuntioides é endêmica da Região Sudeste do Brasil, ocorrendo nos estados de Minas Gerais, São Paulo, Rio de Janeiro (Zappi et al. 2013). Segundo Fundação Biodiversitas (2007) e IUCN (2013) se encontra na categoria Vulnerável (VU). Ocorre nas florestas nebulares da trilha entre as Grutas do Fugitivo e Três Arcos e na Gruta do Cruzeiro, em altitude próxima de 1650 m.s.m. É uma espécie bem distinta das demais Schlumbergera por apresentar cerdas nos ramos. 
D. R. Gonzaga et al.

\section{Agradecimentos}

Os autores agradecem ao Centro de Ensino Superior de Juiz de Fora, a Universidade Federal de Juiz de Fora pelo apoio de trabalho em campo e laboratório, a Fátima Salimena curadora do herbário CESJ, à Rafaela Forzza curadora do herbário RB pelo empréstimo de material e ao Instituto Estadual de Florestas pelo apoio logístico e licença concedida (COL 117/12) para o presente estudo.

\section{Referências}

ANDRADE, B.S.C. \& FORZZA, R.C. 2012. Lentibulariaceae no Parque Estadual do Ibitipoca, Minas Gerais, Brasil. Bol. Bot. Univ. São Paulo 30: 23-35.

BARBERENA, F.F.V.A., CHIAVEGATTO, B. \& BAUMGRATZ, J.F.A. 2010. Melastomataceae nos remanescentes florestais do Parque Estadual do Ibitipoca, Minas Gerais, Brasil. Bol. Bot. Univ. São Paulo 28: 141-157.

BLASER, J.G., EITERER, M., SALIMENA, F.R.G. \& CHAUTEMS, A. 2011. Gesneriaceae no Parque Estadual do Ibitipoca, Minas Gerais, Brasil. Bol. Bot. Univ. São Paulo 29: 1-12.

CETEC. 1983. Diagnóstico ambiental do estado de Minas Gerais. Vol. 1. CETEC. Belo Horizonte.

DRUMMOND, G.M., MARTINS, C.S., MACHADO, A.B.M., SEBAIO, F.A. \&ANTONINI, Y. (Eds.). 2005. Biodiversidade em Minas Gerais: um atlas para sua conservação. 2ed. Fundação Biodiversitas. Belo Horizonte.

FERREIRA, C.S.A.M., TROVÓ, M. \& FORZZA, R.C. 2011. A família Eriocaulaceae no Parque Estadual do Ibitipoca, Minas Gerais, Brasil. Bol. Bot. Univ. São Paulo 29: 19-35.

FERRERO, R \& MELLO-SILVA, R. 2011. Droseraceae do Parque Estadual do Ibitipoca, Minas Gerais, Brasil. Bol. Bot. Univ. São Paulo 29: 13-18.

FORZZA, R.C., MENINI NETO, L., SALIMENA, F.R.G. \& ZAPPI, D. 2013. Flora do Parque Estadual do Ibitipoca e seu entorno. Editora UFJF. Juiz de Fora.

FUNDAÇÃO BIODIVERSITAS. 2007. Listas das Espécies da Flora Ameaçadas de Extinção do Estado de Minas Gerais. http://www.biodiversitas.org.br/listas-mg/lista_floramg.asp.

GONZAGA, D.R., ZAPPI, D.C., FURTADO, S.G. \& MENINI NETO, L. 2014. Cactaceae na Serra Negra, Minas Gerais, Brasil. Rodriguésia 65(2): 443-453.

HUNT, D., TAYLOR, N. \& CHARLES, G. 2006. The new cactus lexicon.Dh books. Milborne Port, UK.

IUCN 2013.IUCN Red List of Threatened Species.Version 2013.1. Disponível em: www.iucnredlist.org.

LOPES, J.C. \& MELLO-SILVA, R. 2012. Annonaceae do Parque Estadual do Ibitipoca, Minas Gerais. Bol. Bot. Univ. São Paulo 30: 157-164.

MENINI NETO, L., ALVES, R.J.V. \& FORZZA, R.C. 2007. A subtribo Pleurothallidinae (Orchidaceae) no Parque Estadual do Ibitipoca, Minas Gerais, Brasil. Bol. Bot. Univ. São Paulo 25: 253-278.
MENINI NETO, L., FORZZA, R.C. \& ZAPPI, D. 2009. Angiosperm epiphytes as conservation indicators in forest fragments: A case study from southeastern Minas Gerais, Brazil. Biodivers. Conserv. 18: 3785-3807.

MONTEIRO, R.F. \& FORZZA, R.C. 2008. A família Bromeliaceae no Parque Estadual do Ibitipoca, Minas Gerais, Brasil. Bol. Bot. Univ. São Paulo 26: 7-33.

SALIMENA-PIRES, F.R. 1997. Aspectos fisionômicos e vegetacionais do Parque Estadual do Ibitipoca, Minas Gerais, Brasil. In G.C. Rocha (coord.). Anais do $1^{\circ}$ Seminário de Pesquisa sobre o Parque Estadual do Ibitipoca. Núcleo de Pesquisa em Zoneamento Ambiental da UFJF. Juiz de Fora, p. 61-60.

SILVA, S.R., ZAPPI, D.C., TAYLOR, N. \& MACHADO, M. (orgs.). 2011. Plano de ação nacional para a conservação das cactáceas. Série Espécies Ameaçadas $n^{\circ} 24$ Instituto Chico Mendes. Brasília.

SOUZA, V.C. \& LORENZI, H. 2012. Botânica sistemática: guia ilustrado para identificação das famílias de Angiospermas da flora brasileira, baseado na APG III. Ed. 3. Instituto Plantarum. Nova Odessa.

TAYLOR, N.P. \& ZAPPI, D.C. 1991. Cactaceae do Vale do Jequitinhonha (Minas Gerais). Acta bot. bras. 5: 63-69.

TAYLOR, N.P. \& ZAPPI, D.C. 1997.Nomenclatural adjustments and novelties in Brazilian Cactaceae.Cact. Consensus Initiatives 3: 7-8.

TAYLOR, N.P. \& ZAPPI, D.C. 2004. Cacti of Eastern Brazil.Royal Botanic Gardens.Kew.

THIERS, B. 2013.Index Herbariorum: A global directory of public herbaria and associated staff.New York Botanical Garden's Virtual Herbarium.http://sweetgum.nybg.org/ih/

VITTA, F. 2002. Diversidade e conservação da flora nos campos rupestres da Cadeia do Espinhaço em Minas Gerais. In E.L. Araújo, A.N. Moura, E.V.S.B. Sampaio, L.M.S. Gestinari \& J.M.T. Carneiro (eds.). Biodiversidade, conservação e uso sustentável da flora do Brasil. Universidade Federal Rural de Pernambuco/Sociedade Botânica do Brasil. Recife, p. 90-94.

ZAPPI, D.C. 1990. Flora da Serra do Cipó, Minas Gerais: Cactaceae. Bol. Bot. Univ. São Paulo 12: 43-59.

ZAPPI, D.C. \& TAYLOR, N.P. 2003.Flora de Grão-Mogol, Minas Gerais: Cactaceae. Bol. Bot. Univ. São Paulo 21: 147-154.

ZAPPI, D.C., AONA, L.Y.S. \& TAYLOR, N. 2007. Cactaceae. In M.G.L. Wanderley, M.G.L., G.J. Shepherd, T.S. Melhem \& A.M. Giulietti (eds.). Flora fanerogâmica do Estado de São Paulo. Instituto de Botânica. São Paulo, vol. 5, p. 163-193.

ZAPPI, D.C. \& TAYLOR, N.P. 2008. Diversidade e endemismo das Cactaceae na Cadeia do Espinhaço. Megadiversidade 4: 111-116.

ZAPPI, D.C., TAYLOR, N.P., SANTOS, M.R. \& LAROCCA, J. 2014. Cactaceae. In: Lista de Espécies da Flora do Brasil. Jardim Botânico do Rio de Janeiro. Disponível em: <http://floradobrasil.jbrj.gov.br/jabot/floradobrasil/FB70>. Acesso em: 03 Mar. 2014. 